\title{
Streptomyces tsukubaensis Fermentation Using Brazil Nut Oil to Enhance Tacrolimus Production
}

\author{
Séforah Carolina Marques Silva ${ }^{1 *}$, Wilson Murilo Ferrari ${ }^{1}$, Jean Vinícius Moreira ${ }^{1}$, Telma Teixeira Franco ${ }^{1}$, Marco \\ Aurélio Cremasco ${ }^{1}$
}

${ }^{1}$ Department of Engineering Processes, School of Chemical Engineering, State University of Campinas, Campinas, Brazil

Corresponding Author: Séforah Carolina Marques Silva, MD, Department of Engineering Processes, School of Chemical Engineering, State University of Campinas, Campinas, Brazil. Email: seforahc@gmail.com

Received May 8, 2019; Accepted August 7, 2019; Online Published September 12, 2019

\begin{abstract}
Introduction: Tacrolimus is a medication mainly used as immunosuppressant, but also plays as an important role in the treatment of dermathoses and eye diseases. It is a secondary metabolite produced during fermentation from Streptomyces tsukubaensis. Investigations have been conducted in order to enhance the tacrolimus production, since it is the greatest industrial bottleneck related to this process. Some strategies have been adopted in order to solve this problem, such as the usage of a genetically modified bacteria and changes in the exogeneous feeding, and providing vegetable oils as nutrient sources. The present study has investigated the influence of the Brazil nut (Bertholletia excelsa) oil as a carbon source in the fermentation.

Materials and Methods: The fermentative process was conducted in an orbital shaker at $28^{\circ} \mathrm{C}$ and $130 \mathrm{rpm}$ during 168 hours. The amount of produced tacrolimus was quantified using HPLC. The sugars and proteins in the medium were measured using the Somogyi-Nelson and Bradford methods, respectively.

Results: According to the results of the present study, a linearity was observed between the amount of consumed sugars and the produced proteins. The highest tacrolimus production was achieved at 96 hours (41.67 mg. L-1), and the biomass production along the fermentation was low.

Conclusions: The use of Brazil nut oil as a carbon source in the fermentation using Streptomyces tsukubaensis was successful, since it increased the tacrolimus production. This point is an advantage of using this vegetable oil compared to traditional sugars.

Keywords: Tacrolimus Production, Vegetable Oils, Brazil Nut Oil, Batch Fermentation, Biotechnology

Citation: Silva SCM, Ferrari WM, Moreira JV, Franco TT, Cremasco MA. Streptomyces tsukubaensis fermentation using Brazil nut oil to enhance tacrolimus production. J Appl Biotechnol Rep. 2019;6(3):109-112. doi:10.29252/JABR.06.03.05.
\end{abstract}

\section{Introduction}

Tacrolimus, also known as FK-506, is a drug first isolated in 1984, that has been widely used to prevent the rejection of transplanted organs, and to also treat dermatoses and eye diseases. ${ }^{1-3}$ It is a 23 membered polyketide macrolide produced during fermentation through different Streptomyces species. The most commonly used is the Streptomyces tsukubaensis. ${ }^{4}$

This medication is interesting to dermatology because it is rapidly absorbed by the epidermis and has less side effects than commonly used drugs. ${ }^{5}$ Besides, as an immunosuppressant agent it is 10-100 times more potent than cyclosporine. ${ }^{6}$ Nevertheless, the treatment cost using tacrolimus is high because of its low productivity. ${ }^{7}$ Up to now, different strategies have been used to solve this problem, including the use of mutant bacteria, ${ }^{8-11}$ and exogenous feeding of precursors in the biosynthesis. ${ }^{12-14}$ Literature reports that $S$. tsukubaensis is capable of metabolizing different carbon sources, such as glucose, maltose, dextrin, soybean oil, cottonseed oil and groundnut oil. ${ }^{14-16}$ Exogenous feeding of oil has played an important role in this bioprocess, since it is a complex source of nutrients which has increased the tacrolimus production. ${ }^{12,14,17}$
The Brazil nut oil is rich in fatty acids and are broken in order to produce coenzymes (acetyl or propionyl) which are known as precursors for the polyketide production. ${ }^{17}$

This study has investigated the influence of the Brazil nut (Bertholletia excelsa) oil on the tacrolimus production. The fermentative process was carried for $168 \mathrm{~h}$ using $S$. tsukubaensis.

\section{Materials and Methods \\ Organism}

The Strain of S. tsukubaensis was acquired from the Leibniz Institute DSMZ.

\section{Culture Conditions}

Streptomyces tsukubaensis culture was maintained on petri dishes containing glucose 4 g. $\mathrm{L}^{-1}$, yeast extract 1 g.L. $\mathrm{L}^{-1}$, malt extract 10 g.L $\mathrm{L}^{-1}, \mathrm{CaCO}_{3} 2$ g. $\mathrm{L}^{-1}$ and agar 12 g.L $\mathrm{L}^{-1}, \mathrm{pH}$ 7.2, and incubated at $28^{\circ} \mathrm{C}$. The seed culture medium and the production medium were based on Turlo et $\mathrm{al}^{14}$ which are presented in Table 1 and Table 2, respectively.

The seed culture medium was prepared, sterilized at $120^{\circ} \mathrm{C}$

Copyright (C) 2019 The Author(s). This is an open-access article distributed under the terms of the Creative Commons Attribution License (http:// creativecommons.org/licenses/by/4.0), which permits unrestricted use, distribution, and reproduction in any medium, provided the original work is properly cited. 
Table 1. Seed Culture Medium Composition

\begin{tabular}{lcccc}
\hline Substance & Malt extract & Yeast extract & Glucose & Maltose \\
\hline Concentration $\left(\mathrm{g} . \mathrm{L}^{-1}\right)$ & 6 & 1.2 & 6 \\
\hline
\end{tabular}

Table 2. Production Medium Composition

\begin{tabular}{|c|c|c|c|c|c|c|c|}
\hline Substance & Brazil Nut Oil & Soy Peptone & Corn Steep Liquid & $\mathrm{MgSO}_{4} \cdot 7 \mathrm{H}_{2} \mathrm{O}$ & $\mathrm{KH}_{2} \mathrm{PO}_{4}$ & $\mathrm{~K}_{2} \mathrm{HPO}_{4}$ & $\mathrm{CaCO}_{3}$ \\
\hline Concentration (g.L-1 $)$ & 30 & 30 & 10 & 0.5 & 2 & 4 & 3 \\
\hline
\end{tabular}

for 20 minutes, inoculated with a Petri dish colony and incubated at $28^{\circ} \mathrm{C}$ on a temperature controlled orbital shaker at $130 \mathrm{rpm}$ for 24 hours in a $250-\mathrm{mL}$ Erlenmeyer baffled flask. The 24 hour-old culture was used as pre-inoculum, and $10 \%$ pre-inoculum was inoculated in a seed culture medium solution, and incubated on a temperature controlled orbital shaker at the same conditions previously described for 24 hours. This culture was used as inoculum. Actually, $10 \%$ inoculum was inoculated in the production medium, incubated at $28^{\circ} \mathrm{C}$ on a temperature controlled orbital shaker at $130 \mathrm{rpm}$ for 168 hours in a 500-mL Erlenmeyer baffled flask. The fermentation batch was performed in duplicates. The Brazil nut (B. excelsa) oil was acquired from Sinergia Cientifica. In order to quantify the tacrolimus production along the fermentative process, $10 \mathrm{~mL}$ of the culture broth were collected each for 24 hours.

\section{Biomass Quantification}

After collecting $10 \mathrm{~mL}$ of the culture broth, $10 \mathrm{~mL}$ of acetone was added to these samples in order to end the fermentation. The resulting content was filtered in pre-weighted filter paper (Whatman $n^{\circ} 1$ ). The cells were washed with deionized water and kept at $80^{\circ} \mathrm{C}$ for 24 hours for drying (Sterilifer - SX1.0).

\section{HPLC Analysis}

The tacrolimus quantification method was based on consolidated literature. ${ }^{14-16}$ After filtration, culture broth samples were purified by evaporating at reduced pressure until the formation of an oily compound. It was added 3.5 $\mathrm{mL}$ of mobile phase (acetonitrile-water 70:30) to the oily compound, which was centrifuged at $4^{\circ} \mathrm{C}$ for 10 minutes. After centrifugation, a two phases mixture was formed. The supernatant was taken and analysed by HPLC (Shimadzu SPD20A) using a C18 column. The flow rate was maintained at $1 \mathrm{~mL} / \mathrm{min}$ and the column temperature at $60^{\circ} \mathrm{C}$. Acetonitrilewater (70:30) was used as mobile phase and the UV detector was kept at $210 \mathrm{~nm}$. The injection sample volume was $20 \mu \mathrm{L}$.

\section{Calibration Method}

The samples used in the calibration method were prepared by adding FK506-standard to $3.5 \mathrm{~mL}$ of mobile phase (acetonitrile-water 70:30). These samples concentrations were 30, 60, 90, 120 and 150 mg.L L $^{-1}$ The FK506-standard was purchased from Sigma-Aldrich (CAS109581-93-3). The quantification of these samples was made using the same conditions cited in the previous item.
Fermentable Sugars and Proteins Quantification

In order to quantify fermentable sugars and proteins, SomogyiNelson and Bradford methods were used, respectively. ${ }^{18,19}$

\section{Results}

Tacrolimus and Biomass Production

By aiming to enhance the tacrolimus production, the fermentative process was conducted based on previous literature. ${ }^{15}$ The tacrolimus production increased along the fermentation, reaching a maximum concentration of 41.87 g.L${ }^{1}$ at 96 hours. After this period of time, the drug concentration reduced until $5.02 \mathrm{mg} . \mathrm{L}^{-1}$ (168 hours). The biomass production was low and reached the highest concentration at 120 hours. The specific tacrolimus production is the ratio between the real drug production and the biomass concentration. The maximum specific production was $4.06 \mathrm{mg} . \mathrm{g}^{-1}$, which is near the specific production reached by Singh and Behera in a fermentation using cottonseed oil as the carbon source. ${ }^{14}$ These results are shown in the Figure 1.

\section{Proteins and Fermentable Sugars Production}

According to Figure 2, the amount of proteins produced during the fermentative process raised. At the beginning of fermentation $(0 \mathrm{~h})$, the proteins concentration in the broth culture was $83.46 \mathrm{mg} . \mathrm{L}^{-1}$ which reached $120.94 \mathrm{mg} . \mathrm{L}^{-1}$ at the end of fermentation. The biggest increase occurred between 96 and 120 hours. After 120 hours, the proteins concentration

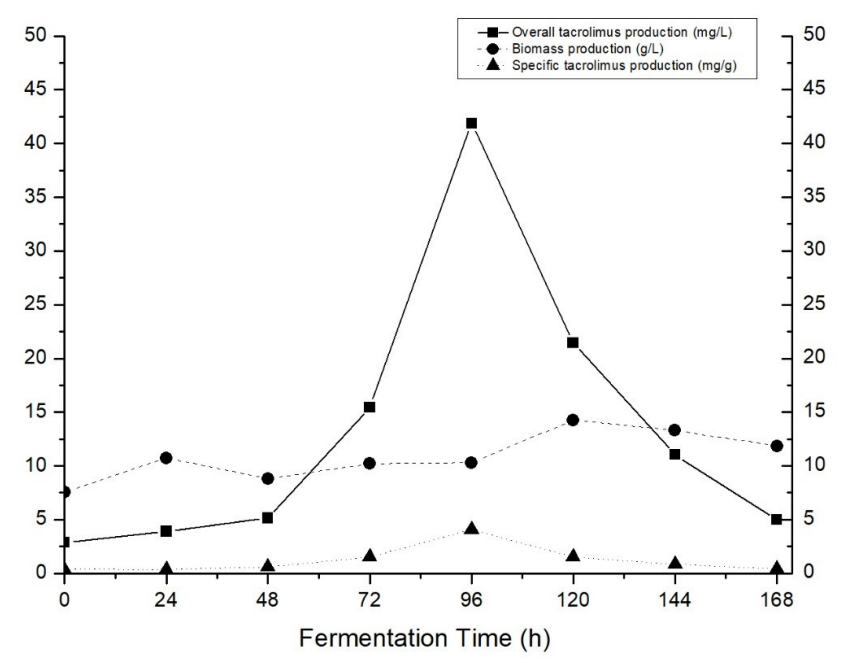

Figure 1. Production of Tacrolimus and Biomass During Streptomyces tsukubaensis Fermentation in the Presence of Brazil Nut Oil. 


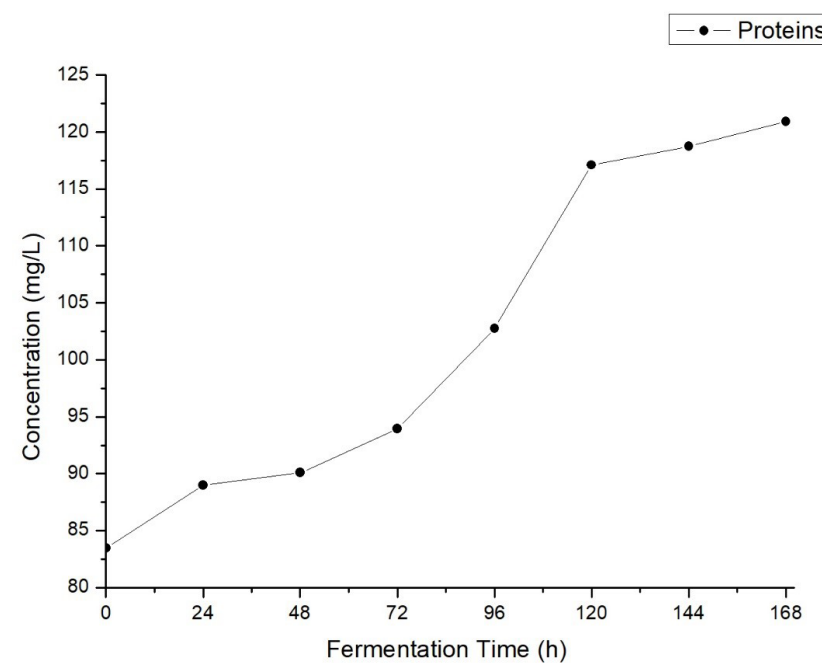

Figure 2. Proteins Concentration Along the Fermentative Process Conducted in the Presence of Brazil Nut (Bertholletia excelsa) Oil.

did not vary significantly.

Figure 3 shows the fermentable sugars behavior during fermentation. The amount of sugars was consumed along the process. The initial concentration was 522.04 g.. $\mathrm{L}^{-1}$ and the final was $254.56 \mathrm{~g} . \mathrm{L}^{-1}$. The greatest decrease occurred in the first 72 hours.

\section{Discussion}

The use of vegetable oils as an alternative carbon source has been an efficient alternative to boost the tacrolimus production during fermentation..$^{12,14,16,17}$ In the present research, the Brazil nut (B. excelsa) oil was used because it contains sugars, amino acids, proteins, vitamins, lipids and fatty acids, ${ }^{20,21}$ that may be tacrolimus precursors. Besides, the concentration of 30 g.L.-1 was used based on a previous study conducted by Singh and Behera, ${ }^{14}$ which achieved reasonable tacrolimus production through fermentation of S. tsukubaensis, using this oil concentration. Also, literature says that high carbon concentrations in the fermentation medium may inhibit the secondary metabolites production. ${ }^{22}$ Therefore, concentrations higher than 30 g.L $\mathrm{L}^{-1}$ are not recommended. Figure 1 shows that the highest concentration of tacrolimus obtained was $41.87 \mathrm{mg} . \mathrm{L}^{-1}$, which is greater than the concentration reported on literature, reached in a fermentation conducted using glucose as the carbon source. ${ }^{15}$ This result was expected and agreed with the results of other papers which used other vegetable oils as carbon sources. ${ }^{12-14} \mathrm{It}$ is believed that one of the factors which regulates the bacterial production of secondary metabolites, such as FK506, is the response to nutrients. ${ }^{12}$ By analyzing previous research, it is possible to realize that all oils that were successful at improving the tacrolimus production were rich in linoleic acid, ${ }^{14,23,24}$ which is an unsaturated fatty acid. ${ }^{25}$ This fatty acid is also a major component of the Brazil nut oil, what may indicate that the linoleic acid is a FK506 precursor. It is worth mentioning that the tacrolimus concentration decrease at 120 hours is not predicted by literature. ${ }^{11,13,15}$

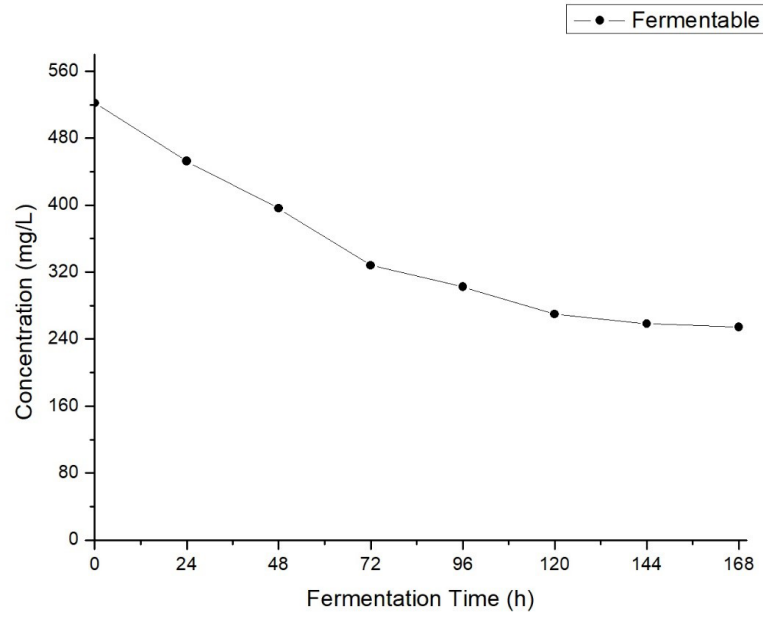

Figure 3. Fermentable Sugars Concentration Along the Fermentative Process Conducted in the Presence of Brazil nut (Bertholletia excelsa) Oil.

The biomass production reached its highest values from 120 to 168 hours, which probably corresponds to the death phase, characterized by the unavailability of nutrients resulting in cellular death. ${ }^{26,27}$ From 48 to 96 hours, the biomass production almost remained constant because biomass formation competes with secondary metabolites biosynthesis. ${ }^{28}$

The amount of proteins increased during the tacrolimus biosynthesis. It is actually known that proteins are consumed and produced along the fermentative process, ${ }^{12}$ so in the present study the producing rate was higher than the consuming rate, which may be considered as a problem to this drug purification. On the other hand, the amount of fermentable sugars decreased along the process. These sugars were mainly supplied to the S. tsukubaensis through the culture broth and are catabolized to produce energy. The production of secondary metabolites, such as tacrolimus, is a bacterial response to a stress condition (reduction of nutrients, for example). ${ }^{28}$ Figures 1 and 3 show that the greatest tacrolimus production occurred at 96 hours, when the amount of fermentable sugar available in the culture broth had already diminished, what is in agreement with the literature.

\section{Conclusions}

The usage of Brazil nut oil (B. excelsa) as a carbon source in $S$. tsukubaensis fermentation increased the tacrolimus production and at the same time did not stimulate the biomass increase, which makes this vegetable oil a feasible option to replace traditional carbon sources. Future studies should investigate the influence of the linoleic acid in the FK506 production, since all fermentations using oils containing this substance were successful at enhancing tacrolimus production. Also, the proteins production and the fermentable sugars consumption occurred as expected. These results may be useful for pharmaceutical industries focused on enhancing tacrolimus production, particularly in Brazil, since this vegetable oil is an affordable native product. 


\section{Authors' Contributions}

SCMS conducted the fermentation and quantification of FK506; JVM and WMF helped to write the manuscript; TTF and MAC supervised the project.

\section{Conflict of Interest Disclosures}

The authors declare they have no conflicts of interest.

\section{Acknowledgments}

This project was supported by CAPES. The authors would like to thank this institution for all their support and financing.

\section{References}

1. Kino $T$, Hatanaka $H$, Hashimoto $M$, et al. FK-506, a novel immunosuppressant isolated from a Streptomyces. I. Fermentation, isolation, and physico-chemical and biological characteristics. J Antibiot (Tokyo). 1987;40(9):1249-1255. doi:10.7164/ antibiotics.40.1249.

2. Gupta AK, Adamiak A, Chow M. Tacrolimus: a review of its use for the management of dermatoses. J Eur Acad Dermatol Venereol. 2002;16(2):100-114. doi:10.1046/j.1468-3083.2002.00380.x.

3. Erdinest $\mathrm{N}$, Ben-Eli $\mathrm{H}$, Solomon A. Topical tacrolimus for allergic eye diseases. Curr Opin Allergy Clin Immunol. 2019;19(5):535543. doi:10.1097/aci.0000000000000560.

4. Barreiro C, Martinez-Castro M. Trends in the biosynthesis and production of the immunosuppressant tacrolimus (FK506). Appl Microbiol Biotechnol. 2014;98(2):497-507. doi:10.1007/s00253013-5362-3.

5. Dé Tran QH, Guay E, Chartier S, Tousignant J. Tacrolimus in dermatology. J Cutan Med Surg. 2001;5(4):329-335. doi:10.1177/120347540100500409.

6. Matsumoto S, Otake H, Sekine M, Uehara T, Miyatani H, Mashima H. Appropriate timing of discontinuation of tacrolimus therapy for refractory ulcerative colitis. Clin Drug Investig. 2019;39(8):737744. doi:10.1007/s40261-019-00795-4.

7. Vaid S. A novel fermentation fed batch process for producing the immunosuppressant Tacrolimus (FK-506), using the mutant microorganism Streptomyces sp. utilizing vegetative oil as sole source of carbon in production medium. US patent. 2007; vol. 142424 , p. A1.

8. Du W, Huang D, Xia M, Wen J, Huang M. Improved FK506 production by the precursors and product-tolerant mutant of Streptomyces tsukubaensis based on genome shuffling and dynamic fed-batch strategies. J Ind Microbiol Biotechnol. 2014;41(7):1131-1143. doi:10.1007/s10295-014-1450-3.

9. Huang D, Li S, Xia M, Wen J, Jia X. Genome-scale metabolic network guided engineering of Streptomyces tsukubaensis for FK506 production improvement. Microb Cell Fact. 2013;12:52. doi:10.1186/1475-2859-12-52.

10. Jung S, Moon S, Lee K, Park YJ, Yoon S, Yoo YJ. Strain development of Streptomyces sp. for tacrolimus production using sequential adaptation. J Ind Microbiol Biotechnol. 2009;36(12):1467-1471. doi:10.1007/s10295-009-0634-8.

11. Li Y, Liang S, Wang J, Ma D, Wen J. Enhancing the production of tacrolimus by engineering target genes identified in important primary and secondary metabolic pathways and feeding exogenous precursors. Bioprocess Biosyst Eng. 2019;42(7):10811098. doi:10.1007/s00449-019-02106-9.

12. Wang J, Liu H, Huang D, Jin L, Wang C, Wen J. Comparative proteomic and metabolomic analysis of Streptomyces tsukubaensis reveals the metabolic mechanism of FK506 overproduction by feeding soybean oil. Appl Microbiol Biotechnol. 2017;101(6):24472465. doi:10.1007/s00253-017-8136-5.

13. Wang $\mathrm{C}$, Liu J, Liu H, Liang S, Wen J. Combining metabolomics and network analysis to improve tacrolimus production in Streptomyces tsukubaensis using different exogenous feedings. J Ind Microbiol Biotechnol. 2017;44(11):1527-1540. doi:10.1007/ s10295-017-1974-4.

14. Singh BP, Behera BK. Regulation of tacrolimus production by altering primary source of carbons and amino acids. Lett Appl Microbiol. 2009;49(2):254-259. doi:10.1111/j.1472765X.2009.02652.x.

15. Turło J, Gajzlerska W, Klimaszewska M, Król M, Dawidowski M, Gutkowska B. Enhancement of tacrolimus productivity in Streptomyces tsukubaensis by the use of novel precursors for biosynthesis. Enzyme Microb Technol. 2012;51(6-7):388-395. doi:10.1016/j.enzmictec.2012.08.008.

16. Martínez-Castro M, Salehi-Najafabadi Z, Romero F, et al. Taxonomy and chemically semi-defined media for the analysis of the tacrolimus producer 'Streptomyces tsukubaensis'. Appl Microbiol Biotechnol. 2013;97(5):2139-2152. doi:10.1007/ s00253-012-4364-x.

17. Kim HS, Park YI. Lipase activity and tacrolimus production in Streptomyces clavuligerus CKD 1119 mutant strains. J Microbiol Biotechnol. 2007;17(10):1638-1644.

18. Nelson N. A photometric adaptation of the Somogyi method for the determination of glucose. J Biol Chem. 1944;153(2):375-380.

19. Hammond JBW, Kruger NJ. The Bradford Method for Protein Quantitation. In: Walker JM, ed. New Protein Techniques. Humana Press; 1988. p. 25-32. doi:10.1385/0896031268.

20. Chunhieng T, Pétritis K, Elfakir C, Brochier J, Goli T, Montet D. Study of selenium distribution in the protein fractions of the Brazil nut, Bertholletia excelsa. J Agric Food Chem. 2004;52(13):43184322. doi:10.1021/jf049643e.

21. Müller $\mathrm{CH}$. The cultivation of Brazil nut. In portuguese: A cultura da castanha-do-Brasil. Brasília: Embrapa; 1995. p. 65.

22. Sanchez S, Demain AL. Metabolic regulation of fermentation processes. Enzyme Microb Technol. 2002;31(7):895-906. doi:10.1016/S0141-0229(02)00172-2.

23. Mishra A, Verma S. Optimization of process parameters for tacrolimus (FK 506) production by new isolate of Streptomyces sp. using response surface methodology. J Biochem Technol. 2012;3(4):419-425.

24. Mo S, Lee SK, Jin YY, Oh CH, Suh JW. Application of a combined approach involving classical random mutagenesis and metabolic engineering to enhance FK506 production in Streptomyces sp. RM7011. Appl Microbiol Biotechnol. 2013;97(7):3053-3062. doi:10.1007/s00253-012-4413-5.

25. Rozendaal A, Macrae AR. Interesterification of oils and fats. In: Lipid Technologies and Applications. Routledge; 2018: 223-263.

26. Wang $C$, Huang D, Liang S. Identification and metabolomic analysis of chemical elicitors for tacrolimus accumulation in Streptomyces tsukubaensis. Appl Microbiol Biotechnol. 2018;102(17):75417553. doi:10.1007/s00253-018-9177-0.

27. Monod J. The growth of bacterial cultures. Annu Rev Microbiol. 1949;3(1):371-394.

28. Hwang K-S, Kim HU, Charusanti P, Palsson BØ, Lee SY. Systems biology and biotechnology of Streptomyces species for the production of secondary metabolites. Biotechnol Adv. 2014;32(2):255-268. doi:10.1016/j.biotechadv.2013.10.008. 